\title{
EXPERT MEDICAL TESTIMONY IN COMPENSATION PROCEEDINGS
}

\author{
Ruth A. YeRION*
}

The use of expert medical testimony in legal proceedings, in both criminal and civil cases, has for many years been'the subject of attack and the object of proposed reform. While the brunt of the attack has been borne by the psychiatric expert who testifies on the question of sanity in murder trials, the medical expert called in personal injury actions or the contest of wills has not been free from criticism. Members of the legal profession and the public generally have condemned expert medical testimony because of its partisan character and because it may be bought. A former Chairman of the Committee on Uniform Judicial Procedure of the American Bar Associątion once said that expert testimony was popularly looked upon as "a safe legal way to buy a verdict." I It is also emphasized by members of the bench and bar that since the function of the expert is to guide the jury or the court to a correct conclusion on matters apart from their own knowledge or experience, the issues are clouded rather than clarified where expert testimony is introduced because expertsparticularly medical experts-disagree. ${ }^{2}$ Members of the medical profession have also criticized the use of expert testimony in legal proceedings, but their protests are directed against what they allege are the inflexible rules of procedure and evidence. They argue that the procedure under which a court trial is conducted wastes their time, interferes with their practice and frequently subjects them to indignities, ${ }^{8}$ and that the rules of evidence surrounding the hypothetical question, which is the usual means through which they must put their opinions in the record, tend to obscure rather than to reveal the truth.

It is difficult to say how much of the criticism leveled against expert medical evidence and the method of handling it is justified. By way of extenuation, it is

- A.B., 1915, University of Alabama; LL.B., 1927, Yale Law School. Referee of Workmen's Compensation Claims for the New York State Department of Labor since 1934. Research Assistant, Yale Law School, I927-I929; investigator into workmen's compensation administration for the Commonwealth Fund, 1929-1933. Member of the New York Bar. Contributor to legal periodicals.

${ }^{3}$ Shelton, Greater Efficacy of the Trial of Civil Cases (1928) $32 \mathrm{Lnw}$ Notes 45.

'See Foster, Expert Testimony, Prevalent Complaints and Proposed Remedies (1897) Ix HARv. L. Rev. 169; Frazer, Expert Testimony, Its Abuses and Uses (1902) 50 AM. L. Rec. 87; Morgan, Expert Medical Testimony (1928) $2 x$ LAWYER \& BANKER 28r; Lee, Expert Testimony (I933) I Kans. CITY L. Rev. 8.

-Moss, The Practicing Physician in Court (1929) 15 A. B. A. J. 497; Anderson, Expert Testimony, Its Evils (1929-30) FLA. STATE Bar Ass'v L. J. x8; White, Judicial versus Administrative Process at the Prosecution State (1935) 25 J. CruM. L. \& Cunar. 851. 
urged that medical experts are human beings and human beings will always disagree. In the field of medicine, particularly, there are many and conflicting schools of thought and this gives room for genuine disagreement. It is likely that the specialist, if he is worth his salt, will have developed strong convictions and opinions bearing on his field and that therefore he will be a zealous advocate of those opinions when called upon to testify. It is to be expected, then, that the party to a controversy who needs just those opinions to fortify his case will call that specialist in his behalf. Moreover, the medical expert, like experts in other fields, may have the facts on which his opinion is desired presented to him both before and during trial by an attorney who emphasizes only those most favorable to his client or his theory of the case. The result is that the expert has a one-sided and hence unfair picture before him. In either case, where the expert is called because of his convictions, or where certain facts of the case are omitted or improperly stressed, it cannot truthfully be said that his testimony is dishonest. Despite all these excuses, however, the fact still remains that the testimony of the expert almost invariably favors the side which produces and pays him; and that when both sides produce expert witnesses the jury or the court who must decide the issues is likely to remain in the dark.

The criticisms of the medical fraternity against the lawyer's way of handling expert evidence are also both fair and unfair. It is true that the way in which most court trials are conducted, with all the witnesses summoned to appear on a day certain, does waste the time of the medical expert and keep him from his practice; for it is necessary to lay the groundwork of the case by the evidence of the parties or other lay witnesses before the expert is called to the stand. This means he must be held in readiness, but must wait his turn. He must also, after direct examination, submit to a cross examination which is often gruelling and sometimes, at least to a thin-skinned individual, insulting as well. Yet a severe cross examination may be necessary, for if the expert is not well qualified or if his opinions are biased, it is only through a vigorous cross examination that these facts will be brought to light. If the expert is both able and honest, he need have little fear of the cross examination. As for the hypothetical question, it is true that it is governed by rules of evidence. Summarized briefly, ${ }^{4}$ the chief restrictions applied in the majority of states are that the facts assumed in such question must be based on evidence which is not only legally admissible, but which has already been admitted into the record; that these facts must be relevant to the issue and of sufficient detail and completeness to elicit an intelligent opinion. Material and undisputed facts must be included, but where the evidence already introduced is conflicting, the hypothetical question, under the majority rule, need not include all of the evidence but only such part of it as the counsel framing the question may reasonably assume to have been established. The form of the question must be such that the expert witness may answer with a "reasonable degree of certainty" and not by pure speculation, and the answer must

4 I WigMoRe, EVIDENCE (2d ed. 1923) \$\$672-689; Note (1909) 9 CoL. L. Rev. 635. 
be "yes" or "no." It is the yes or no answer and the rule that the question need not contain all the facts which the opposing side claims to have been proved to which the medical experts mainly object. The evidential rules just outlined do often make the hypothetical question of unwieldy length and detail, as well as misleading. To this the lawyers reply that the expert may be required to state the bases of his opinion and that other hypotheses based on other facts in the record may be put before him. One eminent jurist ${ }^{b}$ once said of the hypothetical question that he would not recom. mend it as a "form of literature," but he argued it was effective in getting at the truth.

If the doctors and the lawyers are at odds on what has caused expert evidence to fall into disrepute, they are in singular unanimity as to the remedy to be applied, namely, that at least one expert witness must be selected by an impartial source, by either the court or other governmental agency or by some non-political body of experts. The cure prescribed points to the cause of the disease which has fallen upon expert testimony; it is not so much its character or method of handling as it is the instrumentality through which it is selected. A few states have already tried different variations of the proposed remedy in both criminal and civil cases, ${ }^{\circ}$ but while the reform has apparently worked well, the idea has been slow in gaining ground. How does the workmen's compensation tribunal deal with the medical expert and his testimony? And do the same criticisms which are made of expert medical testimony in legal proceedings apply when it is introduced at compensation hearings?

It is important first to consider how far legal rules of evidence must be observed under compensation laws. Those of seven states are administered by the courts, ${ }^{7}$ in the remaining thirty-nine by administrative commissions. In the majority of the statutes of commission states, and in one court-administered state, Louisiana, there is a provision to the effect either that procedure at compensation hearings must be as simple and summary as reasonably may be, or that the compensation officials in the conduct of hearings shall not be bound by common law or statutory rules of evidence or technical rules of procedure. The wording of these provisions might seem to remove most evidential restrictions from the trial of compensation claims; but the courts have generally held that a compensation award, to be sustained, must be supported by at least some competent legal evidence. 8 There has been, however, one liberalizing effect of these provisions as interpreted by the courts, and that is that hearsay evidence is admissible, although it will not in and of itself, when uncorrob-

\footnotetext{
${ }^{8}$ Hand, Historical and Practical Considerations Regarding Expert Testimony (1901) Is Harv. L. Rev. 40.

- See I Wigmore, Evidence (2d ed. 1923) 5563, n. 7; Supplement (1934) 28r-284.

Those slates are Alabama, Louisiana, New Hampshire, New Mexico, Tennessee, Wyoming and Rhode Island. The last mentioned state is sometimes classed with the commission states, since there is a Labor Department as part of the state government; but since disputes may be carried directly to the courts, it is more properly classed with the court-administered jurisdietions. Only two states, Arkansas and Mississippi, are now without compensation statutes.

- Carroll v. Knickerbocker Ice Co., $2 \times 8$ N. Y. 435, I13 N. E. 507 (1916), is the leading case on this subject and has been followed in most compensation jurisdictions.
} 
orated by competent legal evidence, be sufficient to uphold an award. This interpretation tends to ease the formality of compensation hearings and to lessen the number of objections in the record, but it must be admitted that in the end it leads to the fairly strict application of the rules of evidence in compensation hearings. The arrangement of calendars, the order in which witnesses are taken, the number of adjournments granted and the degree of formality observed at hearings are all matters within the rule-making power of the commissions who administer the law. While the same rules of procedure do not apply in any two compensation states, one generalization can safely be made, namely, that the atmosphere in which compensation hearings are conducted in the commission states is considerably less stiff and formal than in the courts. The parties to the controversy, their representatives and witnesses, are all seated around the hearing table, with the presiding commissioner or referee, stenographer and clerk. The witnesses in most jurisdictions do not have to stand when they are sworn, usually there is no formal "summing up" by the counsel for either party, nor are there many long drawn out colloquies between counsel and officials as to whether particular evidence is material or admissible. This procedure is time-saving and puts the parties and their witnesses more at ease than the formality of a court trial. Furthermore, compensation officials in most states grant preferences on their calendars to those cases in which physicians appear, oftentimes suspending the trial of a claim where only lay witnesses are testifying in order to put the medical witness on the stand; and if a certain specialist cannot arrange to be present on the day first appointed for hearing, it frequently happens that the case is set over for hearing on the day best suited to the witness' convenience. To the observer of compensation proceedings in many states, it is obvious that a marked degree of consideration is shown to the medical expert, regardless of the party by whom he is produced.

Any physician specializing in a given field may, of course, be produced by either party to a compensation case; but as a practical matter, such specialist is usually one who has considerable insurance company practice. To get at the reason for this, one must turn again to the statutes which, in all but a few jurisdictions, place the choice of physician treating a compensation claimant with the employer. Since the employer customarily insures medical, as well as cash, benefits with an insurance company, the latter becomes the real agent in selecting the physician or specialist who treats the injured worker. This has led, particularly in large industrial centres, to the concentration of compensation practice in certain groups of physicians whose livelihood is derived chiefly from the insurance companies. And this applies to the specialist or expert, as well as to the attending physician or general practitioner. While both the insurance company and the claimant have the privilege of producing expert testimony, in reality the company is the party who produces by far the greater proportion of it, since the company alone is always in possession of sufficient funds to pay the expert. If enough money is involved in the claim, the injured man may 
and often does bring in an expert in his own behalf, whose opinions are invariably in complete contradiction to those of the company's expert. When this happens and expert testimony is not forthcoming from a disinterested source, the compensation official is in the same dilemma as the judge or jury in a court trial when experts disagree; and if only the company produces expert witnesses, the compensation offcial must either decide all such cases for the insurance company, or disregard the experts altogether. In an endeavor to meet this situation a number of compensation laws from their inception created a staff of state medical examiners attached to the compensation commission to examine claimants at the behest of the commissioners and give opinions as to diagnosis, disability, causal relation of the condition to the injury, or other medical question in dispute. ${ }^{9}$ Among such jurisdictions are large industrial states like New York, California and Ohio. Several states have also provided that the compensation commission may, on its own motion, refer injured workers to specialists outside of the compensation department, but selected by the commission, to render to it an impartial opinion on any medical aspect of the case. Among these states are Massachusetts, Pennsylvania, Georgia, Wisconsin and, since July I, I935, New York.

New York's experience with the production and handling of expert medical testimony in compensation cases is sufficiently typical and perhaps the most interesting, for New York is the most important industrial state, over 500,000 industrial accidents yearly being reported in prosperous years and around 300,000 annually since the depression. Ever since the enactment of its compensation law, in $19 \times 4$, a division of medical examiners has been part of the administrative set-up in each compensation district of the state and has been the source of most of the impartial medical opinion, both expert and ordinary, produced in that jurisdiction. During the course of compensation hearings in any district of New York, those claimants whose disability is still in dispute are referred by the referee to the state physician for examination; their cases are then held aside until the medical report is received from the state doctor. If either side objects to the contents of the report, the medical examiner is called to the stand for cross examination. It frequently happens that one of the parties or the referee may at that time put a hypothetical question to the examining physician. It is open to question whether the state medical examiner in the ordinary case can be termed an expert; however, since most of the state doctors have spent some years in compensation work, and since a number of them have specialized and have been assigned to examine cases involving their specialty, there is rarely an objection to their qualifications and the referee may and usually does accept such testimony as

\footnotetext{
- Illinois, Maryland, Massachusetts, Pennsylvania, Georgia, and Virginia also fall in this group, and the seven states, which have exclusive state insurance funds-Nevada, North Dakota, Oregon, Washington, West Virginia and Wyoming, in addition to Ohio, have medical advisers attached to the state funds. In some states, even where the law makes no direct provision for a state medical staff or for the appointment of impartial experts to examine compensation claimants, the compensation offeials sometimes call in specialists to examine and pass on difficult medical cases. See Hookstadt, Comparison of Workmen's Compensation Insurance and Administration (1922) BuzL. No. 301, U. S. Bureau of Labor Stats. 57,
} 
expert. Where the case is exceptionally hard-fought or where it involves complicated or serious conditions, such as mental disease, epilepsy, tuberculosis, cancer, cardiac or gynecological conditions, etc., to name but a few, the referee who has heard the previous testimony in the case often calls the chief medical examiner to the witness stand and propounds to him a hypothetical question based upon the history of accident and the medical findings which have been introduced in evidence. When the chief examiner has given his opinion, the party whose side has been adversely affected by his testimony may cross examine. In these cases, the chief examiner may or may not have examined the claimant during the course of the case, but usually he has. In death claims, the testimony of the state doctors is not based in any part upon a physical examination, unless a period of disability, during which the claimant was able to come to the Compensation division for a hearing, has preceded death. It is, then, apparent that much of the expert testimony which comes from the state physicians in disability, if not in death claims, is based not only on the record but also on at least one and frequently several physical examinations. This renders the testimony of greater weight, for the doctor has a surer foundation for his conclusions and is less likely to be confused or to change his opinion under cross examination. The testimony of the state doctors is only evidence to be considered and weighed with that produced by the parties, and the referee may act upon any evidence in the record; in case of conflict, however, the opinion of the state examiner usually turns the scale.

There remains a type of case in which the state physician cannot render an accurate opinion either from having the record put before him or through such physical examination as the facilities of the Compensation division permit. Where the claimant is accused of malingering, or where his condition is so obscure that there is.wide difference of opinion as to diagnosis, it may be necessary for the claimant to be hospitalized and observed for a period of days or longer, or subjected to certain difficult tests to reach a correct conclusion. It is even more essential in getting at the truth for such observation or tests to be conducted by a specialist who is chosen by neither side to the controversy, but by an impartial source. Before July I, I935, the procedure adopted in such cases in New York was for the chief medical examiner to recommend that the claimant be observed by an outside specialist selected by the Director of the Compensation Bureau. However, since the state made no appropriation to pay for such specialist, the consent of the insurance company had to be obtained, since it paid the bill. Some companies were glad to give their consent in a complicated or suspicious case, while others refused to give it in any case. By the amendment of the law in 1935 , the Industrial Board is given authority on its own motion, and the referee on the recommendation of the chief medical examiner, to require the examination of any claimant by a specialist, the latter to be designated by the Industrial Commissioner from a panel of specially qualified physicians submitted by the county medical society. The cost of such impartial examination is thrown 
upon the employer or insurance company. Under both the old and new provisions of the law, the report of the impartial specialist is placed in the file of the case and the losing side may call the specialist for cross examination. As a matter of fact, however, this is rarely done. As with the testimony of the state doctors, the compensation official may accept or reject the impartial specialist's opinion, since it is only evidence to be considered with the other evidence adduced; but in the vast majority of cases, the impartial opinion is relied on in the final determination of the claim.

The preceding paragraphs have outlined the sources of and the procedure through which impartial medical testimony, most of it expert, is secured in New York compensation proceedings. The necessity for obtaining some impartial medical opinion in these cases in any jurisdiction, which means the selection of the expert by a disinterested party, cannot be stressed too emphatically, as certain studies in New York in recent years have shown. The New York State Department of Labor, for a period of two weeks in 1930, conducted an unannounced experiment. ${ }^{10}$ Every injured worker who came into the information room complaining that he was still ill and had been discharged from medical treatment too soon by the employer's or insurer's doctor, was sent to the examining room and examined by the assistant chief medical examiner. About sixty per cent of such workers were found to be in need of further medical treatment. In November, 1932, the Cullman Committee, which had been appointed by Governor Roosevelt over a year before to study the medical costs of the New York Compensation Law, reported ${ }^{11}$ that a study of a cross-section of seriously controverted compensation cases revealed that the testimony of physicians regarding causal relation between accident and ensuing disability, and also as to the extent of disability, was closely correlated with the financial interests of the parties who employed them. Where the carrier and the claimant had both produced medical testimony, the battle of the experts was on. The Committee further reported that in twenty-two cases sent to one impartial specialist by the Department of Labor over a period of eighteen months, where the subject of causal relation was involved, the impartial specialist found in favor of the claimant in fifteen cases out of the twentytwo.

Both the Cullman Committee, and in 1934, the Pool Committee, ${ }^{12}$ which had been appointed by Governor Lehman to continue the study of medical problems under the New York Compensation Act, recommended that the choice of physician be taken away from the employer or insurance carrier and that the claimant be given a limited choice of physician from a panel of physicians named by medical societies as qualified to perform compensation practice. In 1935, these recommendations were

${ }^{20}$ See Frances Perkins, Review of Medical and Hospitalization Costs in Workmen's Compensation Cases (1932) BuII. No. 577, U. S. BuREaU of Labor Stats. 27, 35.

${ }^{21}$ See N. Y. Times, Dec. 23, 1932, Pp. 1, 8, for a summary of that report and its recommendations. Report of the Committee to Review Medical and Hospital Problems in Connection with Workmen's Compensation Insurance, submitted by the Cullman Committee to Governor Roosevelt in Dec., 1932.

${ }^{2} N$. Y. Times, Dec. 31, 1933, Pp. 1, 12, contains an outlino of the report and recommendations of the Pool Committee. 
enacted into law, the employer or carrier being given the right to have its own physician examine the claimant at reasonable intervals, in order to check on the treatment and conclusions of the panel doctor. It was noted above that the Industrial Board and the referees were given authority by the new law to refer claimants to impartial specialists on their own motion. The rôle of the state medical examiner remains the same under the new provisions as under the old; as a practical matter, however, the examinations by the state physician in future may be more greatly needed as a check on the treatment and opinions of the claimants' doctors, whereas in the past their effect in many cases was to counteract the conclusions of the insurers' physicians.

In any discussion of medical testimony in compensation proceedings it is important to consider the extent to which impartial medical evidence, coming either from state physicians or impartial specialists unconnected with the law's administration, is used. State compensation departments do not collect statistics on this subject, but an occasional study of compensation administration in various jurisdictions touches upon the matter. Pennsylvania was mentioned as one of the states whose law gave the compensation officials power to appoint impartial physicians or surgeons to examine compensation claimants and report thereon. There is also a medical staff attached to the compensation division of the Pennsylvania Department of Labor and Industry. In that state, where the employer or carrier has choice of physician, neither the state doctors nor the outside impartial specialists are used to any great degree. The number of physicians employed as examiners in the compensation division has usually not exceeded four in number for the entire state, and these serve only part time. From June I, 1929 , to June I, r93I, only $\$ 2,600$ of the state's funds were expended for examinations by impartial physicians or surgeons. ${ }^{13}$ A recent study of the compensation law and its workings in Pennsylvania pointed out ${ }^{14}$ that in a cross-section of controverted cases, "impartial medical testimony was virtually nonexistent." In Pennsylvania, therefore, the compensation officials who must pass upon contested cases rely on the experts produced by the interested parties, as in court trials in most jurisdictions.

In contrast to the situation in Pennsylvania is that of Massachusetts, where the claimant has free choice of physician. There the duties of the state medical advisers, of whom there are usually two employed on part time, are not to pass upon the condition of claimants, although that is occasionally done, but rather to advise the Industrial Accident Board on medical matters and to pass on medical bills submitted by claimants' physicians. The cases in which disability, diagnosis, causal relation, etc., are in dispute are referred to physicians selected from a panel of impartial specialists outside of the department. This panel is drawn up by the Industrial Accident Board.

\footnotetext{
${ }^{23}$ These figures were furnished the writer in 193 I by the Department of Labor and Industry of the State of Pennsylvania.

${ }^{16}$ Horlacher, The Results of Workmen's Compensation in Pennsylvania (1934) 40 SpEc. BuLL., PA. DEP'T OF LABOR AND INDUSTRY, Pt. I-b, P. I2.
} 
The compensation act of Massachusetts gives the Board authority to send claimants to these specialists for examination, fixes the fee for this at $\$ 5$ except in extraordinary cases, where a reasonable sum in addition may be allowed, and provides that the report of such specialist shall be admissible as evidence provided both the "employee and the insurer have seasonably been furnished with copies thereof." In the fiscal year 1928-1929, there were 3,300 examinations by impartial specialists chosen by the Board, ${ }^{15}$ the cost of these examinations being $\$ 22,960$ (payable by the insurance companies, according to the law). In the same period, there were approximately 6,000 contested cases, so that in a little over half of this number the impartial specialist was used. Since the law permits the impartial report to be admitted in evidence without identification, it is only on rare occasions that one of.the interested parties calls the impartial specialist for cross examination. In Massachusetts, then, the impartial medical expert in compensation proceedings is relieved from the disagreeable burden of testifying and being cross examined in most cases.

In describing the New York procedure for securing impartial medical testimony in compensation cases, it was noted that much the greater proportion of such evidence is given by the state physicians. The number of cases in New York which are referred to an outside impartial specialist has been very few when compared with those which are submitted to the state doctors. The recent change in the New York law, however, by which the compensation officials on their own motion may refer claimants to specialists unconnected with the administration will in all probability increase the number of these examinations. Statistics are not available as to the total number of cases sent for examination to the state physicians in a given period, nor as to the-total number in which the state doctors are called to testify. However, on the female trial calendar in New York City during the week ending September 20, 1935, 269 cases were heard. Out of this number, there were 90 medical examinations by state physicians, or in almost exactly $33^{1 \frac{1}{3}}$ per cent of the 269 cases. In relatively few of these cases was it necessary for the state doctor to testify, although the report of the examination was acted upon by the referee, and placed in the file, ready to be admitted in evidence on identification if a dispute later arose. It should be noted that not all of the 269 cases were actually contested, since both contested and uncontested claims are scheduled for hearing in New York; nor, of course, were medical questions disputed in all of these claims. Furthermore, the run-of-the-mill case in New York, as in all other compensation states, involves only short periods of disability. If the case reaches the calendar for its first hearing after the disability has ceased, there is no need for a medical examination by the state doctor and the referee is compelled to act on the testimony or reports of the attending physician, whether selected by the insurer or the claimant, for only that physician can speak as to the length of disability after it is over. However, where the question of causal relation is at issue and the claimant has been treated only by the insurer's doctor, who denies

${ }^{25}$ Statistics given the writer by the Secretary of the Industrial Accident Board of Massachusetts in 1930. 
such relationship; it is then important for the protection of the claimant's rights to call upon the state physician for his opinion. It devolves upon the referee to do this, if the claimant is unrepresented by counsel, and sometimes when he is. If the referee is indifferent, he will act upon the testimony of the attending physician only and fail to call the state doctor to the stand. The executives of the New York Department of Labor have urged the referees to use the state doctors to the fullest extent whenever testimony for the claimant is lacking or difficult to produce. It is probable that the system in New York, with its comparatively large staff of state examiners and with the recent amendment to the law permitting a wider use of impartial specialists, has gone as far as any jurisdiction and beyond most in securing impartial medical testimony in compensation proceedings.

Both parties to a compensation claim, and the compensation officials also in every state use the hypothetical question in order to get the opinions of the medical experts into the record. When the claimant is unrepresented by counsel, it is the duty of the commissioner or referee to take the claimant's physician on direct examination, to cross examine the insurer's doctor and to question the state doctor if necessary. If the insurer's physician has been asked by the company's representative to assume only those facts favorable to the insurer, the referee asks the insurer's physician to assume those facts in the record which are favorable to the claimant. When the state doctor is questioned, the referee usually makes the basis of the hypothetical question as broad as possible, for the broader its scope, the fairer is the picture presented to the witness. If the facts which the state doctor is to assume are so contradictory as to compel him to be the judge of the case in replying to the question, or if there are conflicting histories of accident, one of which would favor and the other negative causal relation or disability, the referee customarily presents two hypotheses to the doctor, and then decides which one is the more tenable according to the weight of all the evidence. When the hypothetical question is handled in this manner, with full opportunity for cross examination granted to the losing side, there can be little complaint that the medical experts are misled or confused by the form of the question.

The medical expert who is called upon to testify in the courts in personal injury actions is often heard to protest against the long delay in bringing these cases to trial. If the specialist has treated or examined the plaintiff during the course of his disability immediately following the accident, and the case is not tried until one or two or even more years have elapsed, the doctor must often depend entirely on his records to refresh his recollection. If such records are not kept in voluminous detail, the doctor may be at a great disadvantage when he is called to the stand to testify, either as an expert or as the attending physician. In most compensation jurisdictions, even when the reports from the employer and claimant are filed promptly, it takes two months or more for the contested case to reach the calendar for hearing, although a few jurisdictions, among them New York, improve on this average where the reports 
come in immediately after the accident. While this delay is longer than it should be, nevertheless it is a vast improvement over the conditions in most courts which pass upon personal injury actions, particularly those in large cities, where a delay of one year or even two is not uncommon. ${ }^{16}$

The degree of success which a compensation tribunal attains with expert medical testimony depends on a number of factors, only one of which is of major importance. Compensation procedure, because of its informality and the consideration shown the medical expert in putting him promptly on the stand and in the arrangement of calendars to suit his convenience, is much better adapted to the expeditious production and handling of expert testimony than is the procedure in either criminal or civil cases. But these are relatively minor matters, which go to the form rather than to the substance. The real test is the extent to which compensation administrators make use of impartial, well-qualified medical testimony.

The quality of expert medical evidence when brought in by the interested parties to a compensation claim is no better and no worse than that introduced in court proceedings-some of it is of high calibre, some of it is not, all of it is open to the suspicion of bias to a degree. When the statute does not give compensation authorities power to call upon impartial specialists outside of the administration, and does not create adequate medical staffs as part of the compensation unit, the situation, from the standpoint of justice, is even worse in compensation than in court cases; for in the latter both sides are more likely to be able to pay for expert witnesses; if, then, no light be thrown on the issues, the odds are even between the litigants. In the compensation claim, however, where only one side, the insurance company, is ordinarily able to pay for expert witnesses, the claimant, for whose benefit compensation laws were enacted, is left without protection in the majority of cases.

The impartial medical evidence in compensation proceedings, which means that chosen by the administrators, is on the whole well qualified, and free from the charge of partisanship. The panels from which the impartial specialists, unconnected with the administration, are drawn, are customarily made up by the compensation administrators with the advice of medical experts or medical societies, and contain many specialists eminent in their fields. The state medical staffs may either give full time to their work, as in New York, or part time as in Massachusetts and many other states. In New York, the state physicians are chosen through competitive examination and are appointed under civil service. Where full time is given, the criticism is often heard that the state examiners are underpaid and have little opportunity for advancement unless they leave the state's employ and enter into insurance company practice. While this view has some justification, it is also true that many competent doctors are employed by the state and that they frequently prefer the security of civil service to the uncertainties of private practice, even of insurance

${ }^{10}$ The Supreme Court in New York County, for example, where the more important negligence actions are tried, is said to be two years behind in its calendars at the present time. 
practice. Moreover, the state physicians engaged in compensation work soon become experts in their field; since they must always bear in mind the relation of trauma to disease, they can under competent administration work out certain standards which are very valuable as a guide to the administrator in deciding difficult types of cases. This tends to produce a uniformity of decision in contrast, for example, to the unpredictable outcome of most personal injury actions.

The principal defect with impartial medical testimony in compensation states lies not in its quality or method of handling or selection, but in its scarcity. In many states, the reason for this is because insufficient funds are granted either for adequate state medical staffs or for impartial examinations by outside specialists in all cases where they are needed. In other states, the fault lies with the administrators in failing to take full advantage of the powers or appropriations granted. In solving any problem connected with the administration of justice, there must be competent and honest officials to administer the law; and where compensation officials are the agents in securing impartial testimony, they must always be on the alert to keep off the list of impartial examiners those whose practice is derived in the main either from the insurance companies or from compensation claimants. While this may seem to be a large order, it is not impossible of accomplishment even under the existing systems of procedure. Where this is done and where sufficient power and funds are granted to obtain disinterested medical testimony when needed, most of the evils popularly associated with expert medical testimony will be overcome or greatly lessened. 